\title{
INHALT
}

Vorwort $\ldots \ldots \ldots \ldots \ldots \ldots \ldots \ldots \ldots \ldots \ldots \ldots \ldots$

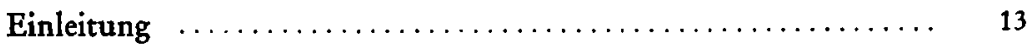

Kapitel 1:

Zur Behandlung des Mythus Gen $3 \ldots \ldots \ldots \ldots \ldots \ldots \ldots, 22$

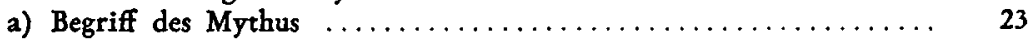

b) Begriff der Vorstellung $\ldots \ldots \ldots \ldots \ldots \ldots \ldots \ldots \ldots \ldots \ldots \ldots, 25$

c) Phänomenologie der religiösen Vorstellung $\ldots \ldots \ldots \ldots \ldots \ldots \ldots, 27$

d) Vorstellung und Gottesbegriff $\ldots \ldots \ldots \ldots \ldots \ldots \ldots \ldots \ldots \ldots .29$

e) Das Begreifen der Vorstellung: die Vernunfthematik ......... 32

\section{Kapitel 2:}

Dialektik der Unschuld $\ldots \ldots \ldots \ldots \ldots \ldots \ldots \ldots \ldots \ldots \ldots \ldots, 38$

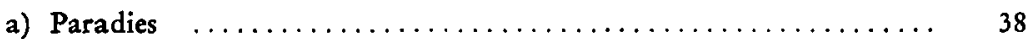

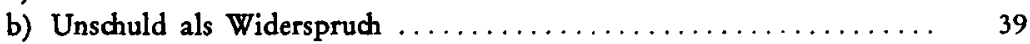

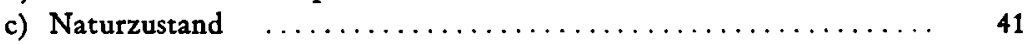

d) Kritik des Vorstellungskomplexes $\ldots \ldots \ldots \ldots \ldots \ldots \ldots \ldots \ldots .43$

e) Logik der Subjektivität $\ldots \ldots \ldots \ldots \ldots \ldots \ldots \ldots \ldots \ldots \ldots, 46$

\section{Kapitel 3:}

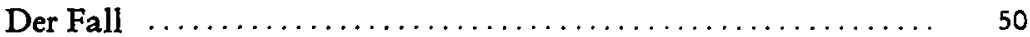

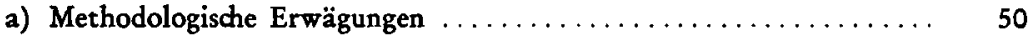

b) Die Entzweiungsthematik $\ldots \ldots \ldots \ldots \ldots \ldots \ldots \ldots \ldots \ldots \ldots, 52$

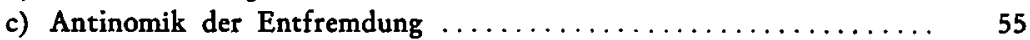

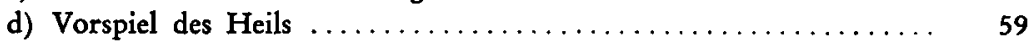

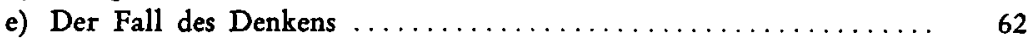

Kapitel 4:

Die Konstruktion des Sündenbegriffs $\ldots \ldots \ldots \ldots \ldots \ldots \ldots \ldots 6 . \ldots \ldots$

a) Konstitution des Selbstbewußtseins als Krise $\ldots \ldots \ldots \ldots \ldots \ldots 65$

b) Radikalisierung des Sündenbegriffs und die Geschichte des
religiösen Bewußtseins $\ldots \ldots \ldots \ldots \ldots \ldots \ldots \ldots \ldots \ldots \ldots \ldots \ldots \ldots \ldots$

c) Transzendentalität des Sündenbegriffs und die Phänomenologie des Sündenbewußtseins $\ldots \ldots \ldots \ldots \ldots \ldots \ldots \ldots \ldots \ldots \ldots, 84$ 
d) Funktion der Erbsündenvorstellung $\ldots \ldots \ldots \ldots \ldots \ldots \ldots \ldots \ldots 90$

e) Zur Möglidkeit einer Theorie der Sünde $\ldots \ldots \ldots \ldots \ldots \ldots \ldots .97$

Exkurs I:

Kierkegaards „Der Begriff Angst“ - Erste Antikritik ....... 106

Kapitel 5:

Sünde und Gottesgedanke $\ldots \ldots \ldots \ldots \ldots \ldots \ldots \ldots \ldots \ldots \ldots \ldots$

a) Selbstbewußtsein und Gottesgedanke $\ldots \ldots \ldots \ldots \ldots \ldots \ldots \ldots \ldots, 117$

b) Das Problem der ${ }_{\text {NNotwendigkeit }}{ }^{\alpha}$ von Sünde $\ldots \ldots \ldots \ldots \ldots \ldots . \ldots 123$

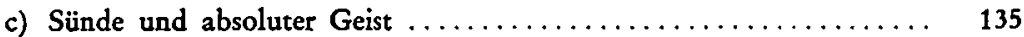

d) Absoluter Geist als Bewegung von "Form ${ }^{\text {« und } \text { "Inhalt }{ }^{*} \ldots \ldots \ldots} 145$

\section{Exkurs II:}

Das Pantheismusproblem - Substanz und Subjekt ......... 154

a) Substanz als Subjekt: Versuch einer Interpretation $\ldots \ldots \ldots \ldots \ldots 155$

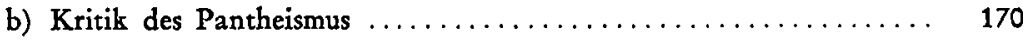

c) Die religiöse Genese des Subjektivitätsprinzips $\ldots \ldots \ldots \ldots \ldots \ldots 178$

d) Pantheismus und Sündenbegriff $\ldots \ldots \ldots \ldots \ldots \ldots \ldots \ldots \ldots, 189$

Kapitel 6:

Sünde und Versöhnung $\ldots \ldots \ldots \ldots \ldots \ldots \ldots \ldots \ldots \ldots \ldots, 192$

a) Selbstbewußtsein und Versöhnung $\ldots \ldots \ldots \ldots \ldots \ldots \ldots \ldots \ldots \ldots . \ldots \ldots$

b) Das Problem der Einheit von Gut und Böse ............. 202

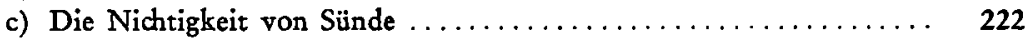

d) Versöhnung und Sittlichkeit $\ldots \ldots \ldots \ldots \ldots \ldots \ldots \ldots \ldots \ldots \ldots \ldots \ldots \ldots \ldots \ldots, 227$

Exkurs III:

Kierkegaards „Die Krankheit zum Tode“ ${ }^{\star}$ Zweite Antikritik ..

Exkurs IV:

Die Hegelkritik J. Müllers $\ldots \ldots \ldots \ldots \ldots \ldots \ldots \ldots \ldots \ldots \ldots \ldots$

Kapitel 7:

Subjektivität als Freiheit $\ldots \ldots \ldots \ldots \ldots \ldots \ldots \ldots \ldots \ldots, 282$

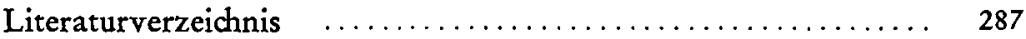

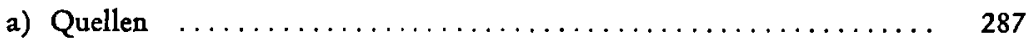

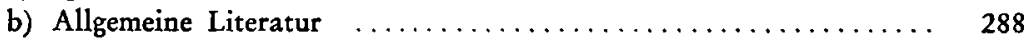

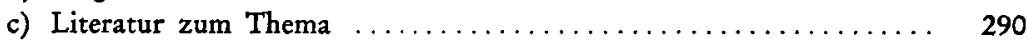

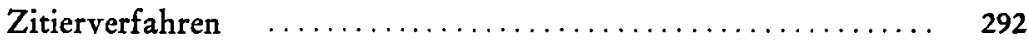

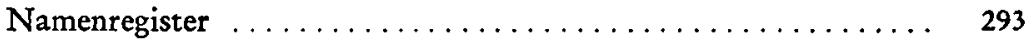

Begriffsregister $\ldots \ldots \ldots \ldots \ldots \ldots \ldots \ldots \ldots \ldots \ldots \ldots . \ldots \ldots$ 
Ein geflidkter Strumpf besser als ein zerrissener; nicht so das Selbstbewußtsein.

Verbotene Frucht, wie der Lorbeer, aber ist Am meisten das Vaterland. Die aber kost Ein jeder zuletzt.

nemlich zu Hauß ist der Geist Nicht im Anfang, nicht an der Quell. Ihn zehret die Heimath. Kolonie liebt, und tapfer Vergessen der Geist. 
